17. Мединцева И.П. Использование MS EXCEL при обучении студентов эконометрике // Научный вестник Волгоградской академии государственной службы. Серия: Экономика. 2011. Т. 2. № 6. С. 93-96.

18. Селевко Г.К. Проблемное обучение // Школьные технологии. 2006. №2. С. 61-65.
19. Хуторской А.В. Практикум по дидактике и современным методикам обучения. СПб.: Питер, 2004. $541 \mathrm{c}$.

20. Плотникова О., Суханова В. Самостоятельная работа студентов: деятельный аспект // Высшее образование в России. 2005. № 1.

\title{
IMPROVEMENTS IN THE FORMATION OF ECONOMETRIC KNOWLEDGE AT TRAINING OF BACHELORS - TEACHERS OF ECONOMIC PROFILE
}

(C) 2016

\author{
Yu.V. Zelepukhin, candidate of technical sciences, head of the Chair of Economical Education \\ O.Yu. Tsybina, senior lecturer of the Chair of Economical Education \\ Samara State University of Social Sciences and Education, Samara (Russia)
}

\begin{abstract}
The concept of modernization of Russian education raises the question about necessity of introduction of profile training to improve and develop the school system of education. It is important that the implementation of ideas to improve education a priority is the presence of expert teachers to work in specialized classes. One of the most difficult is to educate students to work in classrooms socio-economic profile. Future teachers enrolled in the profile "Economics", must use economic, mathematical and econometric methods in solving socio-economic issues, to know the achievements of world economic thought, have a General mathematical culture. To achieve these goals in higher education is taught econometrics. It is an interdisciplinary science, it is based on mathematical and economic knowledge. Over the past 40 years there has been a rapid development of econometrics as a scientific discipline. As evidence of international recognition and importance was the awarding of the Nobel prize in Economics for outstanding research in the field of econometrics scholars such as Ragnar Frisch and Jan Tinbergen, James Heckman and Daniel McFadden. It should be noted that all econometric methods are used more in different publications and studies. To econometrics deeply penetrate the latest information technologies and mathematical methods. Econometrics students, teachers of economic profile has a positive effect on the cognition of the world and the absorption of various knowledge, since the mathematical language is universal and the one who knows how to use it successfully will be able to apply their knowledge in various fields of science and industry. The article is devoted to the improvement of the formation of econometric knowledge at training of bachelorsteachers of economic profile.

Keywords: the concept of modernization of Russian education, economic knowledge, economic thinking, economicmathematical and econometric methods, bachelors-teachers of economic profile, curriculum, basic educational program, Federal state educational standard of higher professional education, training direction «Pedagogical education», professional competences, active learning methods, competence approach to education.
\end{abstract}

\section{МОДЕЛЬ ОХРАНЫ ТРУДА И ЗДОРОВЬЯ СТУДЕНТОВ СПЕЦИАЛЬНОЙ МЕДИЦИНСКОЙ ГРУППЫ В УСЛОВИЯХ ВУЗА}

(C) 2016

Г.М. Ильмушкин, доктор педагогических наук, профессор кафедры высшей математики

O.B. Пархаева, заведующий кафедрой физической культуры и спорта, аспирант

Ю.Е. Судакова, кандидат педагогических наук, доцент кафедры физической культуры и спорта Димитровградский инженерно-технологический институт -

филиал Национального исследовательского ядерного университета «МИФИ», Димитровград (Россия)

Аннотация. В настоящей работе представлен обзор состояния здоровья студенческой молодежи на современном этапе развития образования в РФ, обоснованы факторы, обуславливающие прогресс ряда устойчивых заболеваний, связанных с условиями умственного труда в ВУЗе. На основе изучения имеющихся фактов и путем анализа медицинской и учебной документации Димитровградского инженерно-технологического института-филиала Национального исследовательского ядерного университета «МИФИ» (ДИТИ НИЯУ МИФИ) представлена динамика численности студентов, отнесенных по состоянию здоровья к специальной медицинской группе (СМГ), а также структура заболеваемости по нозологическим признакам. Данный контингент студентов нуждается в особой организации занятий по физической культуре. В этой связи предложено оптимальное структурирование содержания образования по физическому воспитанию студентов СМГ с учетом их физического состояния здоровья, психоэмоциональных характеристик, мотивационно-ценностного отношения к физическому самосовершенствованию, а также широкого внедрения компетентностного подхода в образовательный процесс по физической культуре. При этом физическое воспитание студентов нами рассматривается в контексте охраны труда и здоровья. Тем самым предложена авторская модель охраны труда и здоровья студентов СМГ. В разработанной модели существенное внимание обращается на совершенствование физического воспитания студентов путем внедрения в учебный процесс инновационных средств педагогической коммуникации.

Ключевые слова: учебная деятельность, физическая культура, здоровье, охрана труда, специальная медицинская группа, ценностное отношение, компетентностный подход. 
Постановка проблемы в общем виде и её связь с важными научными и практическими задачами. С учетом тенденции резкого ухудшения физического и психического состояния здоровья студенческой молодежи принципиальное значение имеет четкая персонализация обучающихся специальной медицинской группы. В этих условиях актуализируется проблема совершенствования организации физкультурно-оздоровительной и здоровьесберегающей направленности занятий студентов СМГ в контексте охраны труда и здоровья посредством оптимального структурирования содержания образования по физической культуре и внедрения инновационных форм и дидактических методик обучения. В то же время охрана труда и здоровья студенческой молодежи выходит на первый план с точки зрения укрепления здоровья нации, сохранения генофонда и имеет существенное медико-социальное значение. Студенческая молодежь представляет собой необходимый интеллектуальный, производственный потенциал общества, и от уровня охраны труда и здоровья современной молодежи зависит устойчивость экономического развития и национальная безопасность РФ. Поэтому в сложившейся ситуации разработка инновационных средств и методов работы со студентами, организация и планирование занятий оздоровительной физической культурой для исследуемой группы приобретает особую актуальность и является своевременной задачей, включающей в себя определенную регуляцию интенсивности физической нагрузки, проведение оздоровительных, профилактических и обучающих мероприятий.

Обозначенная проблема в методологическом аспекте нами рассматривается с позиций системного, деятельностного и компетентностного [1-6] подходов реалистической стратегии физического воспитания.

Анализ последних исследований и публикаций, в которых рассматривались аспекты этой проблемы и на которых обосновывается автор; выделение неразрешенных раньше частей общей проблемы. Научными изысканиями, близкими к заявленной нами проблеме, занимались многие исследователи. В частности, Я.С. Вайнбаун, В.И. Коваль, Т.А. Родионова [7, с. 78], ими установлено, что $90 \%$ молодежи имеют отклонения в физическом развитии уже по окончании общеобразовательных школ. Как они констатируют, данный феномен обусловлен ухудшением экологии, неправильным образом жизни, низким уровнем санитарногигиенической культуры, недостаточной двигательной активностью и другими факторами. Или авторы В.Т. Чичикин [8], И.Н. Тимошина, И.М. Купцов, Л.А. Парфёнов [9] рассматривают проблему физкультурного образования учащихся школ, отнесённых по состоянию здоровья к специальной медицинской группе, с точки зрения подросткового возраста.

Масштабность обозначенной проблемы демонстрируют и научные исследования последних лет, которые утверждают тезис о том, что количество студентов с ослабленным состоянием здоровья в отечественных вузах неуклонно возрастает [10, с. 45]. Для данной категории студентов создаются специальные медицинские группы по различным критериям физического состояния студентов, в которых они занимаются физическими упражнениями по специальным программам. Некоторые организационно-педагогические аспекты в этом направлении рассматривались в работах [11-15].
Модель охраны труда и здоровья студентов специальной..

Физические занятия со студентами СМГ требуют, прежде всего, оптимального структурирования содержания образования с учетом различных факторов:

- психофизического их состояния;

- ценностно-мотивационного отношения к физической культуре;

- внедрения инновационных средств педагогической коммуникации;

- широкого внедрения компетентностного и аксиологического подходов к процессу физического воспитания студентов;

- физическое самосовершенствование студентов будущих специалистов для предприятий атомной промышленности с учетом дальнейшей профессиональной деятельности.

Вместе с тем вышеизложенные положения недостаточно изучены в педагогической науке применительно к будущим специалистам атомной отрасли в контексте их охраны труда и здоровья.

Итак, цель настоящего исследования: теоретически обосновать и реализовать эффективные технологии и методики оздоровительных занятий путем оптимального структурирования содержания образовательного процесса по физической культуре со студентами специальной медицинской группы в контексте охраны труда и здоровья.

Целями, в свою очередь, обусловливаются задачи, определяющие содержание совместной деятельности личности педагога и студента, их взаимодействия в процессе учебной деятельности по физической культуре. Тем самым нами выделены целевые задачи исследования, выделим основные из них:

- создание позитивной ценностно-мотивационной среды обучения, направленной на удовлетворение образовательных потребностей личности студента, проявления интереса к физическим упражнениям, а также самоопределения в социальной и производственной деятельности;

- развитие потребности в регулярных занятиях физическими упражнениями и спортом, овладение системой практических умений и навыков, обеспечивающих сохранение и укрепление здоровья, а также приобретение опыта творческого использования физкультурно-спортивной деятельности для достижения стратегических жизненных и профессиональных целей.

Изложение основного материала исследования с полным обоснованием полученных научных результатов. На современном этапе развития общества повышаются требования к уровню общего развития человека и его отношение к образованию. Изменение социокультурной ситуации в стране порождает потребность в таких качествах личности, как ответственность, самостоятельность, инициативность, ведение здорового образа жизни. В связи с этим, целью образования является воспитание гармонично развитой личности, способной к активной жизнедеятельности. Одной из составляющих развитой личности является здоровье. Здоровье молодого поколения является важнейшей ценностью для государства и социума в целом.

В научной литературе и практике все ярче и отчетливее признается особая роль проблемы охраны труда и здоровья учащейся молодежи. В данном случае учебная деятельность рассматривается в спектре умственного труда, к которому относятся работы, связанные с 
приемом и переработкой информации и, тем самым, сопряженные с активизацией сенсорного аппарата, памяти, процессов мышления, эмоциональной сферы, волевых усилий.

Умственный труд имеет ряд особенностей. Чаще всего он связан с длительной работой в закрытом помещении и сидячим образом жизни. Усиленная работа мозга требует большого притока крови к нему, что в свою очередь связано с повышением тонуса сосудов мозга. Это физиологическое повышение тонуса сосудов при неправильной организации труда может перейти в патологическое, что может привести к стойкому повышению артериального давления. Умственный труд, зачастую в сидячем положении приводит к длительному сдавливанию грудной клетки, что ухудшает вентиляционную способность легких и ведет к развитию хронической кислородной недостаточности. При длительной работе сидя создаются также условия для застоя крови в органах брюшной полости и таза, снижается моторная деятельность кишечника, что может привести к нарушению их функции. Умственный труд также является следствием большой нагрузки на зрительный анализатор. Как всякая интенсивная работа, умственный труд неизбежно связан с утомлением, которое приводит к тому, что человеку приходится затрачивать на обычный объем работы больше энергии. В некоторых случаях наступает состояние хронического утомления, которое может закончиться истощением нервной системы или развитием сосудистого заболевания. И все перечисленное в первую очередь свойственно учащейся молодежи. Совокупность перечисленных особенностей жизнедеятельности студенчества стала одной из причин стабильного увеличения количества студентов с ослабленным здоровьем, отнесённых по результатам медосмотра к СМГ для занятий физической культурой. Согласно сложившейся традиции в учебных заведениях, в том числе и высших, выделяют следующую классификацию [8]:

- основную (ОМГ - относятся студенты, не имеющие хронических заболеваний, с достаточно хорошей физической подготовленностью, редко болеющие);

- подготовительную (ПМГ - относятся студенты, не имеющие хронические заболевания, или находящиеся в стадии стойкой ремиссии и не имеющие противопоказания к физическим нагрузкам по программе учебного заведения, часто болеющие);

- специальную (СМГ - относятся студенты, имеющие врожденные и приобретенные хронические заболевания различных систем организма, с ослабленным здоровьем, часто болеющие, с низкой физической подготовленностью, имеющие противопоказания к физическим нагрузкам);

- полностью освобожденные (относятся студенты, имеющие тяжёлые отклонения в состоянии здоровья необратимого характера; как правило, им рекомендуются занятия в кабинетах ЛФК при лечебных учреждениях).

Данные научно-популярной литературы свидетельствуют, что в настоящее время около $40 \%$ всех российских студентов занимаются физической культурой в специальных медицинских группах (СМГ) и около 3$7 \%$ имеют полное освобождение от занятий физической культурой по состоянию здоровья [2].

С целью определения реального уровня здоровья студентов был проведён анализ медицинской и учеб- ной документации за период с 2011 по 2015 гг. в ДИТИ НИЯУ МИФИ. В результате выявлено, что ежегодно увеличивается количество поступающих в данный вуз абитуриентов с нарушениями физического состояния здоровья, что свидетельствует о факте начала негативных изменений в организме молодых людей ещё в подростковом возрасте. В частности, если в 2011 г. к СМГ было отнесено 13,5\% первокурсников, то в 2015г. уже $35,1 \%$ (рис. 1 ).

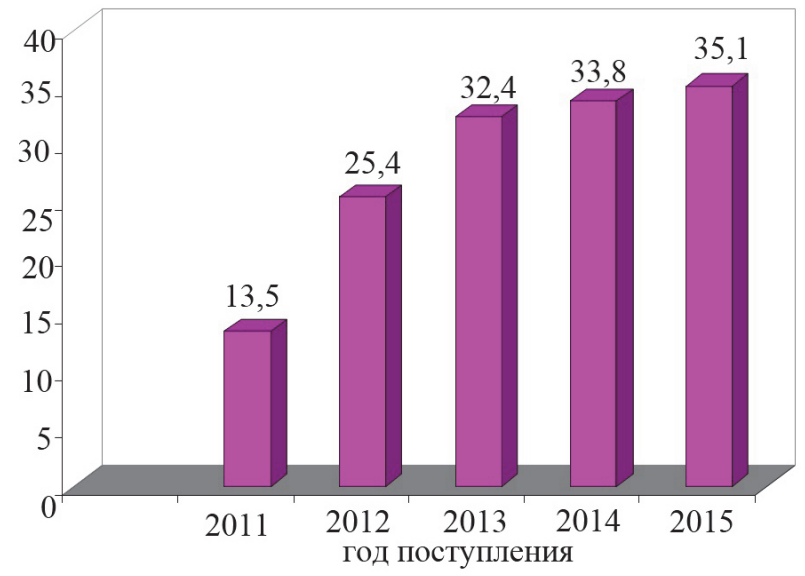

Рисунок 1 - Количество студентов первокурсников ДИТИ НИЯУ МИФИ, отнесенных по состоянию здоровья к специальной медицинской группе

На последующих курсах также выявлено стабильное снижение численности студентов, занимающихся физической культурой в ОМГ, и, как следствие, увеличение количества студентов, либо занимающихся в СМГ, либо освобождённых от учебно-тренировочных занятий (УТЗ) по физической культуре. При этом в структуре заболеваний студентов доминируют заболевания опорно-двигательного аппарата (ОДА) и сердечно-сосудистой системы (ССС). Более того, обнаруживается устойчивая прогрессирующая динамика указанных заболеваний. Аналогичная ситуация складывается и по другим нозологическим группам. Полученные данные полностью согласуются с изложенными выводами и других специалистов, свидетельствующих о следующем [16]:

- в настоящее время наблюдается снижение уровня здоровья выпускников школ и студентов ВУЗов;

- в процессе обучения в вузе здоровье студентов продолжает снижаться либо за счёт прогрессирования уже имеющихся нарушений, либо за счёт возникновения новых;

- самыми распространёнными в студенческой среде являются различного рода нарушения ОДА и ССС;

- стабильно прогрессирующими являются нарушения ОДА, ССС, органов зрения, дыхательной системы (ДС).

О необходимости внедрения инновационных подходов в области охраны труда и здоровья студенческой молодежи свидетельствует также тот факт, что в ФГОС по дисциплине «Физическая культура» [17] регламентируется содержание, направленность и методика проведения УТЗ преимущественно для студентов ОУО. Однако для студентов СУО предусмотрены лишь общие рекомендации, сводящиеся к тому, что при проведении занятий с данным контингентом необходимо учитывать специфику заболеваний, а также показания и противопоказания по двигательной активности. Тем 
самым учебно-методический комплекс дисциплины по физической культуре для студентов СУО разрабатываются кафедрами физического воспитания в вузах РФ с учетом специфики организации и проведения занятий в данных группах.

Изложенное выше ставит на повестку дня разработку и реализацию комплексных мер по охране труда и здоровья студентов СМГ как на уровне государства, так и в рамках конкретного вуза, в частности, ДИТИ НИЯУ МИФИ, что созвучно определению охраны труда в трактовке, приведенной в Трудовом кодексе Российской Федерации [18]. Следовательно, образовательная деятельность со студентами СМГ должна быть конструирована исходя из специфики учебной деятельности как одного из видов трудовой деятельности, а также с учетом их медицинских характеристик, руководствуясь положениями, изложенными в [18].

Таким образом, охрана труда и здоровья студентов представляет собой система мер, разрабатываемых на уровне государства и на уровне конкретного образовательного учреждения ВПО. То есть, нами предлагается двухуровневая модель охраны труда и здоровья студентов ВУЗа, относящаяся к СМГ.

В частности, первый уровень включает следующее:

- создание электронного паспорта здоровья;

- внедрение обязательного всероссийского мониторинга состояния здоровья населения во всех субъектах Российской Федерации;

- совершенствование управления здравоохранением в целях модернизации системы охраны и укрепления здоровья студенческой молодежи, совершенствование законодательства в области охраны труда и здоровья учащейся молодежи и т.д.

\section{Второй уровень:}

- укрепление и расширение материально-технической базы вуза в сфере оздоровления;

- общевузовская трансляция физкультминутки с комплексом лечебной гимнастики для преподавателей, студентов;

- организация повторного медицинского обследования студентов специальных групп с целью контроля за состоянием здоровья;

- совершенствование методики физического воспитания специальных медицинских групп и т.д.

При этом каждый уровень включает как меры общего, так и специального характера относительно охраны труда и здоровья студентов СМГ. Выявленные уровни взаимосвязаны и взаимообусловлены, представляя единый процесс.

Одним из основных направлений общего характера государственной политики в области охраны труда и здоровья населения, в том числе и учащейся молодежи, должно быть создание электронного паспорта здоровья на основе компьютерной модели организма, внедрение которого позволит существенно поднять уровень здравоохранения при уменьшении расходов на эту сферу. Что касается компьютерного мониторинга состояния здоровья населения, то в настоящий момент он осуществляется в 40 субъектах Российской Федерации [19]. Поэтому, другим общим направлением государственной политики в области охраны труда и здоровья населения должно стать создание системы мониторинга в каждом субъекте РФ и его ежегодное проведение должно стать обязательным.
Модель охраны труда и здоровья студентов специальной...

Мерами специального характера на уровне государственной политики должно стать совершенствование системы управления здравоохранением в целях модернизации системы охраны и укрепления здоровья студенческой молодежи. В этих целях необходимо внедрять и развивать многоуровневую и многоэтапную систему медицинской помощи на основе использования стандартов диагностики, профилактики, лечения и реабилитации с учетом распространенности факторов риска в студенческой среде, образа жизни молодежи, адекватности оказания корригирующих мероприятий, лечения и реабилитации с последующей оценкой эффективности.

В настоящее время остается острой необходимость принятия законов, регулирующих вопросы охраны здоровья молодежи, профилактики наркомании в молодежной среде. Около 50 субъектов РФ приняли свои законы о молодежной политике [16]. Эти законы оригинальны по своему содержанию, структурированию, определению приоритетов. Вместе с тем, ни в одном субъекте РФ до сих пор не принят полный пакет документов, охватывающих все стороны жизни и деятельности молодежи, все направления молодежной политики. Поэтому, необходимо полностью унифицировать подходы к осуществлению молодежной политики, в частности в области охраны труда и здоровья молодежи на федеральном уровне и в регионах РФ.

Политика государства по отношению охраны труда и здоровья молодежи должна строиться на принципах партнерства органов государственной власти и личности на основе общности интересов.

Прежде всего, системой мер общего характера на уровне конкретного вуза должно стать укрепление и расширение материально-технической базы в сфере охраны труда и здоровья студенческой молодежи [1923]. В то же время в целях охраны труда и здоровья студентов с ограниченными возможностями необходимо оздоровление вузовской среды обитания. Кроме того, системой мер общего характера на уровне ВУЗа должна стать обязательная общевузовская трансляция утренней физкультминутки с комплексом лечебной гимнастики для преподавателей, студентов. В качестве меры специального характера должно стать повторное медицинское обследование студентов СМГ с целью контроля за состоянием здоровья. Студенты СМГ должны проходить повторный медицинский осмотр не реже 1 раза в семестр.

Результаты педагогических наблюдений, антропометрических измерений и контрольных испытаний среди студентов СМГ ряда специалистов [9,24] показывают, что кроме нозонологического распределения групп студенческой молодежи, имеет физиологические особенности в зависимости от половой принадлежности. Показатели гемодинамики и двигательных возможностей также различны в зависимости от пола. Поэтому необходим гендерный подход к содержанию физического воспитания, который предполагает, прежде всего, применение здоровьесберегающих технологий к выполнению физических упражнений не только с учетом различных заболеваний, но и с разной дозировкой в зависимости от пола.

Особое внимание заслуживает совершенствование методики физического воспитания студентов специальных медицинских групп. Как нам представляется, 
для студентов СМГ целесообразно разработать, апробировать и внедрить в учебный процесс по физической культуре специальный курс по «Хатха-йоге». Уникальной особенностью данной системы упражнений являются то, что они стимулируют гормональные железы и осуществляют массаж внутренних органов. Стимуляция гормональной системы помогает поддерживать сбалансированные эмоции и способствует более оптимистическому отношению к жизни. Предложенная система упражнений особенно подходит людям занятым умственным трудом и имеющим познавательный характер.

Нами успешно реализована оздоровительная методика, включающая несколько оздоровительных блоков: дыхательные упражнения по системе А.Н. Стрельниковой [25], оздоровительная гимнастика, корригирующая гимнастика на базе лечебной физической культуры, оздоровительная ходьба. При этом широко реализуются аксиологический и компетентностный подходы в физической подготовке студентов. Занятие представляет собой несколько блоков упражнений из вышеперечисленных видов оздоровительной физической активности и наполняется в зависимости от состояния здоровья, физического развития и функционального состояния студентов СМГ.

Нами установлено, что дифференцированный подход способствует формированию потребности в регулярных занятиях, что позитивно отражается на состоянии здоровья студентов и увеличивает возможности реализации их личностного потенциала в образовательной и поисково-исследовательской деятельности, a, в конечном итоге, в формировании общекультурных и профессиональных компетенций. Систематические оздоровительные занятия в целом улучшили общее состояние здоровья студентов СМГ. Положительная динамика показателей состояния здоровья студентов способствовала формированию в группе позитивной мотивационной сферы по отношению к занятиям оздоровительной физической культурой.

Bыводы исследования и перспективы дальнейших изысканий данного направления. Разработаны, а также реализованы в образовательном процессе эффективные оздоровительные методики в ходе учебных занятий по физической культуре со студентами СМГ, учитывающие их физические особенности, что позволило им переосмыслить и оценить свои потенциальные физические возможности, повысило чувство собственного достоинства и уверенности в своих силах. В свою очередь, это способствовало проявлению студентами ценностно-смыслового и мотивационного отношения к занятиям физической культуры, пониманию её как высшей ценности развития личности в системе общей человеческой культуры и бытия. В то же время динамично происходило переоценка ими роли и значимости физического воспитания в повседневной жизни и профессионально-личностном развитии.

Итак, внедрение инновационных средств и методов обучения, организация и планирование занятий с оздоровительной физической культурой для студентов СМГ подтвердило актуальность обозначенной проблемы и её своевременность.

Представленные в разработанной модели направления в области охраны труда и здоровья студентов ВУЗа, относящихся к СМГ, не являются исчерпывающи- ми. Они могут быть дополнены и расширены структурно, а также другими оригинальными идеями и предложениями, а также адаптированы вполне к конкретному ВУЗу. Безусловно, требуется дальнейшее исследование по разработке эффективных критериальнооценочных средств достижений по физическому воспитанию студентов СМГ. Авторы данной работы глубоко убеждены, что результаты выполненного педагогического исследования будут способствовать успешному формированию у студентов как общекультурных, так и профессиональных компетенций в соответствии с ФГОС, в целом укреплению и сохранению здоровья студенческой молодежи и могут лечь в основу широкой программы по оздоровлению разных групп населения.

\section{СПИСОК ЛИТЕРАТУРЫ:}

1. Ильмушкин Г.М. Системное моделирование в процессе реализации непрерывной многоуровневой подготовки специалиста: монография. Димитровград: ДИТУД, 2005. 354 с.

2. Королев Ф.Ф. Системный подход и возможности его применения в педагогических исследованиях // Советская педагогика. 1970. № 9. С. 103-116.

3. Селевко Г.К. Опыт системного анализа современных педагогических систем // Школьные технологии. 1996. № 6. С. 5-43.

4. Талызина Н.Ф. Деятельностный подход к построению модели специалиста // Вестник высшей школы. 1986. № 3. С. 10-14.

5. Зеер Э., Сыманюк Э. Компетентностный подход к модернизации профессионального образования // Высшее образование в России. 2005. № 4. С. 23-29.

6. Зимняя И.А. Ключевые компетентности как результативно-целевая основа компетентностного подхода в образовании // Ректор ВУЗа. 2005. № 6. С. 13-29.

7. Вайнбаун Я.С., Коваль В.И., Родионова Т.А. Гигиена физического воспитания и спорта: учеб. пособие для студентов. М.: Академия, 2002. 240 с.

8. Чичикин В.Т. Физическое воспитание школьников специальной медицинской группы: Методическое пособие / под общ. ред. В.Т. Чичикина. Н. Новгород: Центр ФК и ЮС, 2010. 165 с.

9. Тимошина И.Н., Купцов И.М., Парфёнов Л.А. О физкультурном образовании учащихся, отнесённых по состоянию здоровья к специальной медицинской группе // Адаптивная физическая культура. СПб.: СПб ГУФК им. П.Ф. Лесгафта, 2012, Вып. 2 (26). С. 22-24.

10. Пономарев Г.Н. Образование в области физической культуры: физкультурное или физическое? // Вестник Балтийской педагогической академии. Вып. 47. Т. 1: Актуальные научно-педагогические проблемы физической культуры. 2012. С. 25-36.

11. Гритченко Н.В. Основы физического воспитания, врачебного контроля и лечебной физической культуры. М.: Медицина, 1972. 272 с.

12. Забродина Н.П. Работа со специальными медицинскими группами // Физическая культура в школе. 2000. № 6. C. 22-25.

13. Железняк Ю.Д., Петров П.К. Основы научнометодической деятельности в физической культуре и спорте. М.: Академия, 2002. 265 с.

14. Ильмушкин Г.М., Пархаева О.В., Судакова Ю.Е. Воспитание физических качеств у студентов технологического института на занятиях физической культурой // Научное мнение: науч. ж. 2014. № 8. С. 54-61. 
15. Лабунский В.В. Методические рекомендации по физическому воспитанию учащихся, отнесенных к специальной медицинской группе. Тбилиси, 1985. 18 с.

16. Рожков П.А. Развитие физической культуры и спорта - приоритетное направление социальной политики государства // Теория и практика физической культуры. 2012. № 1. С. 2-7.

17. Примерная программа по дисциплине «Физическая культура» (Квалификации (степени) выпускника бакалавр). Министерство образования и науки Российской Федерации.

18. Трудовой кодекс Российской Федерации от 30.12.2001 N 197-Ф3 (ред. от 23.07.2013, с изм. и доп., вступающими в силу с 01.09.2013) // Российская газета, № 256, 31.12.2001.

19. Земсков А.С., Иванчин А.И. Разработка и внедрение компьютерных программ в деятельность учителя физической культуры - проблемы и перспективы // Азимут научных исследований: педагогика и психология. 2015. № 3 (12). С. 13-18.

20. Бакулина Я.С., Ведерников А.В., Гусев А.А. Социально-экономические проблемы в области спорта и физической культуры системы вуза, пути решения и развития // Вестник НГИЭИ. 2015. № 9 (52). С. 18-22.

21. Восколович Н.А., Кугоев И.А. Актуальные аспекты менеджмента в сфере гольфа: управление взаимодействием потребителей услуг и гольф-клубов // Азимут научных исследований: экономика и управление. 2015. № 4 (13). С. 28-31.

22. Федулов И.С., Медведева И.А. Влияние занятий спортом на социально психологические характеристики подростков // XXI век: итоги прошлого и проблемы настоящего плюс. 2014. № 4. С. 183-187.

23. Jihad D.M. Ways of development of militaryphysical training in azerbaijan during the period of independence // Азимут научных исследований: педагогика и психология. 2015. № 4 (13). С. 38-39.

24. Теория и организация адаптивной физической культуры. Т. 2: Учебник в 2 т. / под общ. ред. проф. С.П. Евсеева. М.: Педагогическое общество России, 2011. $448 \mathrm{c}$

25. Щетинин M.Н. Дыхательная гимнастика А.Н. Стрельниковой. М.: Метафора, 2007. 128 с.

\section{MODEL OF LABOUR SAFETY AND HEALTH PROTECTION OF COLLEGE STUDENTS FROM A SPECIAL MEDICAL GROUP}

(C) 2016

G.M. Il'mushkin, EdD, professor, professor of the Chair of Higher Mathematics O.V. Parhaeva, head of the Chair of Physical Culture and Sport, postgraduate student Y.E. Sudakova, $\mathrm{PhD}$, associate professor of the Chair of Physical Culture and Sport Dimitrovgrad Engineering-Technical Institute branch of National Nuclear Research University MEPhI, Dimitrovgrad (Russia)

Abstract. This paper presents an overview of the state of health of students at the present stage of development of education in the Russian Federation, factors are justified which determine the progress of a number of resistant diseases associated with conditions of mental work at the university. On the basis of the facts available and analysis of medical and educational documentation of Dimitrovgrad Engineering-Technical Institute - branch of National Nuclear Research University MEPhI (Diti MEPhI) the paper shows the dynamics of the number of students assigned to a special medical group (SMG), as well as morbidity structure of the nosological status. This group of students have special needs as far as their physical training is concerned. In this regard, the authors suggest the optimal structuring of the content of physical education for the SMG students which is based on their physical health, psycho-emotional characteristics, motivation and attitude to physical self-improvement, as well as the introduction of competence-based approach in physical training class. At the same time physical education is considered in the context of labour safety and health protection. Thus, the authors propose a model of health protection of SMG students. In the model developed, considerable attention is given to improving the students' physical education by introducing innovative pedagogical tools of communication in the educational process.

Keywords: educational activity, physical education, health, labor protection, a special medical group, value, attitude, competence approach.

УДК 371.123

\section{СТРУКТУРА АНАЛИТИЧЕСКОЙ ДЕЯТЕЛЬНОСТИ РУКОВОДИТЕЛЯ ОБЩЕОБРАЗОВАТЕЛЬНОЙ ОРГАНИЗАЦИИ}

(C) 2016

Н.Н. Коваль, методист

Донеикий республиканский институт дополнительного педагогического образования, Донеик (Донеикая Народная Республика)

\footnotetext{
Аннотащия. В статье рассмотрены сложившиеся в педагогике подходы к структурированию и описанию компонентов аналитической деятельности. Представлены различные модели аналитической деятельности: деятельностный подход (Е.В. Назначило, Н.А. Зинчук, В.В. Ягупов, Н.П. Пичугова), системный подход (Л.П. Половенко, О.Н. Ярыгин, А.А. Коростелев), структурно-деятельностный подход (Л.М. Плахова). Охарактеризованы основные компоненты и этапы аналитической деятельности в зависимости от представленного подхода. Акцент сделан на трехмерной модели аналитической деятельности руководителя общеобразовательной организации: технология
} 